\title{
Juan de Ávila: su crítica a la limpieza de sangre y su condición conversa
}

\author{
Juan Ignacio Pulido Serrano** \\ Universidad de Alcalá
}

A Francisco Rupérez

El presente artículo estudia algunos aspectos relativos a la vida y obra de Juan de Ávila, uno de los autores más importantes de la literatura espiritual del siglo XVI español. El hecho de ser descendiente de judíos, por vía paterna, algo que fue bien conocido por sus contemporáneos, y su singular postura frente al problema converso, le causó distintos problemas, entre ellos un proceso inquisitorial ante el tribunal de Sevilla. En este artículo hemos analizado la huella que dejaron estas experiencias personales en sus principales trabajos (Audi, filia, sermones, Epistolario espiritual), en los cuales se expresa su actitud y su pensamiento sobre la polémica cuestión de la limpieza de sangre.

Palabras Clave: Juan de Ávila; Literatura espiritual; Siglo de Oro español; Limpieza de sangre; problema converso; Inquisición; crítica social.

Juan de Ávila: His Critique of the Purity of Blood and his Converso Condition. - Juan de Avila was one of the most important authors of spiritual literature during the $16^{\text {th }}$ century. This article presents the historical persona, focusing on the impact of his Jewish ancestry (on his father's side) on his work and on the reaction to his writings. The fact that he was of Jewish descent, a circumstance well known in his time, and his special vision on the Converso issue, caused him some problems and also dramatic troubles with the Inquisition of Seville. In this article, we analyze through his writings (Audi, Filia, Sermons, Epistolario Espiritual) Juan de Ávila's attitude and thoughts about the "Purity of Blood" in the Iberian tradition.

KeYwords: Juan de Ávila; Spiritual literature; Spanish Golden Age; Purity of Blood; Converso Problem; Inquisition; Social Criticism.

* Este trabajo se ha realizado en el marco del proyecto de investigación El legado de los sacerdotes. El patrimonio del clero secular en Castilla durante el Antiguo Régimen (núm. 11863/PHCS/09), dirigido por el prof. Antonio Irigoyen y financiado por la Fundación Séneca. Agencia Regional de Ciencia y Tecnología de la Región de Murcia. Agradezco a los evaluadores anónimos de Sefarad por sus comentarios críticos y correcciones.

*** jignacio.pulido@uah.es 
En este trabajo pretendemos acercarnos a la figura de Juan de Ávila en su dimensión de personaje histórico, enmarcado dentro del siglo XVI en el que le tocó vivir, para tratar de entenderlo en su tiempo concreto, con los problemas y conflictos en los que se desenvolvió su vida y en los que generó su obra, tanto la escrita como la referida a su acción evangélica. Creo, y dígase desde el comienzo, que en su obra están presentes y expresadas sus vivencias personales, interiorizadas y procesadas vitalmente en sus años de formación en Salamanca, Almodóvar del Campo y Alcalá de Henares, y después, en sus vivencias fruto del apostolado ejercido en Sevilla y en sus localidades vecinas, como Écija, Montilla o Alcalá de Guadaira; también en otras ciudades andaluzas como Granada o Baeza. Experiencias todas ellas que conforman una andadura vital o vividura, en palabras de Américo Castro, que no sólo se expresa en sus obras escritas, el Audi, filia, libro de toda una vida, en su Epistolario espiritual, resultado de las cartas que envió a quienes buscaban consejo en él, o en sus sermones y tratados, recogidos por sus discípulos y publicados en diferentes ediciones. Tales experiencias están además presentes en la orientación paulina que dio a su actividad evangélica durante los años de su apostolado andaluz'.

Esta es la idea que queremos exponer en este estudio. No hay duda de que Juan de Ávila fue un converso de ascendencia judía, y que esta circunstancia personal era conocida en su tiempo, como han señalado los autores de su biografía más completa y actualizada, Luís Sala Balust y Francisco Martín Hernández². Además, su condición como cristiano nuevo, en tiempos tan duros y conflictivos en España a raíz de esta cuestión, le pasó factura en vida, aspecto que está todavía por explicar en detalle pero del que tenemos numerosos datos. Álvaro Huerga lo señalaba en un trabajo pionero sobre Juan de Ávila y ha insistido en ello posteriormente, abriendo un nuevo camino para el análisis que nosotros hemos querido seguir en el presente estudio ${ }^{3}$. Creemos que estas circunstancias pueden

${ }^{1}$ Las referencias que hago a sus textos proceden de San Juan de Ávila, Obras completas. Nueva edición crítica [en lo sucesivo, Juan de Ávila, Obras completas]. Introducción, edición y notas de L. Sala Balust y F. Martín Hernández (Madrid: BAC, 2000-2003 [4 vols.]).

${ }^{2}$ Juan de Ávila, Obras completas, vol. I, 18-19.

3 Á. Huerga, O.P., «Conversos, alumbrados y tomismo en la escuela de Juan de Ávila», Teología espiritual XVIII, núm. 53 (1974), 229-252. IDEM, «Conversos y alumbrados en el 
explicar en buena medida la postura beligerante de Juan de Ávila frente a la exclusión social que sufrían los conversos y hacen más comprensible su oposición a la cultura de la limpieza de sangre, la cual fue imponiéndose paulatinamente en la sociedad durante el siglo XVI ${ }^{4}$. Este es un aspecto, por otra parte, inédito en los estudios dedicados a este hombre principal de la cultura y espiritualidad del siglo XVI, asunto que sin embargo a nosotros nos parece importante para entender muchas de sus ideas. En nuestra opinión, la actitud beligerante de Juan de Ávila en la cuestión conversa debió ser temprana, manifestada ya en sus primeras misiones y predicaciones por tierras andaluzas, allá por los años de 1526 y 1532, siendo una de las causas que le llevaron a las cárceles de la Inquisición en Sevilla. Posteriormente, su crítica a la limpieza de sangre aparecerá expresada por escrito en distintos lugares de su obra, en los que expone sus ideas de manera extensa y bien fundamentada en argumentos teológicos. Juan de Ávila expuso esta crítica de forma tan directa y con un lenguaje tan bello y humano que nos preguntamos cómo es posible que no haya sido detectada antes por otros estudiosos que se han venido ocupando del problema converso o de la obra de este reciente doctor de la Iglesia.

\section{Primeros datos biográficos y formación en Alcalá de Henares}

Juan de Ávila nació en la localidad manchega de Almodóvar del Campo en 1499 o $1500^{5}$. Fue hijo de un matrimonio acaudalado del lugar, formado por Alonso de Ávila, converso de judío, y Catalina Xijón, procedente de una familia hidalga. Cuando rondaba los catorce años, fue enviado a estudiar leyes a la universidad de Salamanca, donde pasó cuatro años sin conseguir graduarse, experiencia que de acuerdo a sus biógrafos le resultó amarga. Alfonso Torres nos dice que aquellos fueron cuatro años negros que se vieron truncados por su condición de cristiano nuevo,

huerto de Juan de Ávila», capítulo X de su libro Historia de los alumbrados, vol. V: Temas y personajes (1570-1630) (Madrid, Fundación Universitaria Española, 1994), 237-259.

${ }^{4}$ A. A. Sicroff, Los estatutos de limpieza de sangre. Controversias entre los siglos XV y XVI (Madrid: Taurus, 1985). J. HeRnÁndez Franco, Sangre limpia, sangre española. El debate sobre los estatutos de limpieza de sangre (siglos XV-XVIII) (Madrid: Cátedra, 2011).

${ }^{5}$ N. GonzÁlez Ruiz y J. L. Gutiérrez García, Juan de Ávila. Apóstol de Andalucía (Madrid: BAC, 1991); Juan de Ávila, Obras completas, vol. I, 15-18. 
aunque no aporta pruebas documentales que acrediten esta opinión ${ }^{6}$. La cuestión, como han señalado Sala Balust y Martín Hernández, está todavía por aclarar ${ }^{7}$. En 1517 Juan de Ávila volvía a su localidad natal para refugiarse en una vida de recogimiento y dedicada a la meditación. Este primer intento de lanzarse al mundo para hacer carrera como hombre de leyes había resultado fallido. Tras los tres años de retiro en Almodóvar del Campo emprendió una nueva trayectoria. Se decidió entonces por los estudios de teología, pero esta vez en una universidad distinta, la de Alcalá de Henares.

Juan de Ávila pasó años decisivos en Alcalá de Henares en lo que se refiere a su formación, cuya universidad había abierto sus puertas poco más de una década antes. Fueron años en los que maduró su determinación de dedicarse al servicio de Dios y de la Iglesia. Allí estuvo entre 1520 y 1526. Esta vez no sería como la anterior ocasión frustrada, la salmantina; de Alcalá salió ordenado como sacerdote, con el título de bachiller en Artes, con profundos conocimientos en sagradas escrituras y en teología, pero sobre todo, decidido a vivir como apóstol misionero. Sobre estos años decisivos cabe preguntarse cuál fue el ambiente universitario y religioso que respiró en Alcalá de Henares y que tanto influyó en su formación y en la orientación que dio a su vida posterior ${ }^{8}$. Sabemos que la Universidad de Alcalá, recién fundada por el Cardenal Cisneros, arzobispo de Toledo, tenía como objetivo convertirse en un semillero de nuevos hombres, bien preparados en conocimientos teológicos, dispuestos a participar en un ambicioso proyecto de evangelización, tanto en el Viejo como en aquel Nuevo Mundo recién descubierto ${ }^{9}$. La universidad complutense se creó para formar los cuadros humanos que debían acometer esta doble misión: renovar la Iglesia y extenderla allá donde todavía no

\footnotetext{
${ }^{6}$ A. Torres, S.J., «El Beato Juan de Ávila, Reformador», Manresa XVII (1945), 193201: 194.

${ }^{7}$ Juan de Ávila, Obras completas, vol. I, 23-26.

${ }^{8}$ S. Aguadé Nieto, «Juan de Ávila y el movimiento de Alcalá», en M. D. Rincón (coord.), El Maestro Juan de Ávila. Aspectos del humanismo español del siglo XVI (en prensa; agradezco al autor que me permitiera leer su trabajo).

9 Á. Huerga, «La Teología en la Universidad de Alcalá (1508-1515)», en A. Fliche y V. MArtín, Historia de la Iglesia, vol. XVII: El Renacimiento (Valencia: Edicep, 1974), 585-616.
} 
había llegado. Era necesario, pues, intensificar la comunicación del mensaje de Dios expresado en sus evangelios, para lo cual era preciso también mejorar lo que se sabía de los textos sagrados, objetivo desarrollado por el equipo de humanistas que elaboraron la Biblia Políglota.

Esta formación universitaria, que en Alcalá quiso ser principalmente teológica por voluntad de su fundador, se abrió a recoger todas las vías del conocimiento de Dios que entonces se debatían y que se había implantado en las distintas universidades de la cristiandad. Se respiraba en la de Alcalá un aire de apertura y de libertad, en la que estas tres vías del conocimiento -tomista, escotista y nominalista- tenían cabida, cada una de ellas con su respectiva cátedra de teología. Todos estos ambiciosos propósitos dieron al ambiente universitario de Alcalá un aire de profunda renovación y de decidida determinación, del cual Juan de Ávila no pudo ser ajeno durante los años de su estancia. Además, en esos años de la década de 1520, la universidad se estaba convirtiendo en un centro receptor y divulgador de las corrientes erasmistas. Las obras de Erasmo, príncipe del humanismo cristiano reformador, se traducían, imprimían, leían y enseñaban en Alcalá, haciendo de su universidad un foco de primer orden en la difusión de sus ideas, adoptadas por muchos jóvenes que aquí se fueron formando, quienes después las llevaron a otros lugares en los que acabarían desarrollando sus actividades. A decir por Marcel Bataillon, el erasmismo español nace en esos años de 1522 a 1526, siendo la universidad de Alcalá uno de sus primeros focos irradiadores, donde jóvenes estudiantes y maestros de vocación humanista le dieron su rumbo inicial ${ }^{10}$. Eran tiempos de apertura y renovación, fruto de una secular corriente de reformas religiosas que echaban sus raíces en la Castilla de finales del siglo XIV y del siglo XV. Coincidía con el clima que se daba en otras partes de la cristiandad, consecuencia de la nueva espiritualidad de la Devotio moderna, y que hacia 1520 empezaba a dar señales de un mal encaje en los marcos políticos que se estaban construyendo por parte de las nuevas monarquías, animadas a ejercer un mayor control sobre las Iglesias y sobre los creyentes en sus respectivos ámbitos territoriales, y a imprimir sobre ellos un dinámica uniformadora que debía podar el exceso de diversidad.

\footnotetext{
${ }^{10}$ M. Bataillon, Erasmo y España (Madrid: Fondo de Cultura Económica, 1995), $155-159$
} 
En este sentido, las corrientes humanistas de profunda renovación espiritual dejaron correr sus aguas por campos que fueron calificados como heréticos por el poder monárquico. Eran tiempos en los que la situación en el conjunto de la cristiandad se estaba enrareciendo, más aún cuando estas aspiraciones de reforma religiosa fueron presa de intereses políticos, enfrentados unos con otros en una intransigente competencia. Así, en el corazón de Castilla, el Consejo de la Suprema Inquisición marcó en 1525 algunos de los límites infranqueables de esta renovación religiosa, declarando heréticas algunas de estas propuestas, las cuales fueron calificadas como «alumbradas» o «iluministas». Se desató entonces su persecución para evitar su propagación, emprendiéndose acciones represivas, dirigidas algunas de ellas contra círculos presentes en Alcalá y en otras localidades vecinas. El propio Ignacio de Loyola, presente en Alcalá de Henares entre 1526 y 1527 , fue procesado por las autoridades inquisitoriales y episcopales, problemas de los que tampoco se libraría años después Juan de Ávila, ni otros estudiantes y profesores procedentes de la universidad alcalaína $^{11}$.

En este movimiento de renovación espiritual, tan presente en la ciudad universitaria de Alcalá, hubo un indiscutible protagonismo de grupos integrados por cristianos nuevos. Esta circunstancia explica la complejidad de estas corrientes religiosas que afloran entorno al ideal de reforma así como la percepción que de ellos se tuvo en la época. Como es bien sabido, en las últimas décadas del siglo XV y en las primeras del siglo XVI, las sociedades españolas se vieron atravesadas por violentas agitaciones sociales y políticas a causa de la numerosa presencia de cristianos nuevos en los núcleos urbanos. El problema venía de atrás, y las conversiones de 1492 no hicieron más que aumentar y extender una conflictividad que se había hecho crónica, y Alcalá de Henares no se vio libre de esta cuestión. La universidad atrajo a muchos cristianos nuevos procedentes de diversos lugares de la península: el equipo de humanistas que reunió Cisneros para acometer los proyectos complutenses, con la Biblia Políglota como objetivo fundamental, contaba con reconocidos conversos como Alfonso de Zamora, Pablo Coronel y Alfonso de Alcalá entre otros; también se

${ }^{11}$ M. Bataillon, Los jesuitas en la España del siglo XVI (Valladolid: Junta de Castilla y León, 2010). Sobre los problemas de Ignacio de Loyola en Alcalá de Henares, véase el capítulo I «Los apóstoles de Alcalá», 65-112. 
integraron en los cuadros del profesorado alcalaíno y, en mayor número, entre la masa de estudiantes que pasaron por las aulas. El ambiente de apertura, renovación y libertad debió animar a muchos cristianos nuevos a elegir esta universidad para formarse, donde además la imposición de los estatutos de limpieza de sangre fue más tardía que en otras universidades como en la de Salamanca o Valladolid ${ }^{12}$.

De acuerdo a este estado de cosas, fue generalizándose la sospecha que vinculaba unas realidades con otras: corrientes de reforma religiosa, erasmismo, cristianos nuevos y herejías alumbradas. Así, muchos entendían que las corrientes de renovación erasmista y su buena acogida por parte de los círculos de cristianos nuevos habían convertido aquel impulso renovador en propuestas religiosas heréticas, como podía comprobarse con los casos de los llamados conventículos de alumbrados. Bien es cierto que la conferencia de Valladolid convocada por el Inquisidor General en 1527 no había condenado el erasmismo y que Erasmo contaba con numerosos y poderosos apoyos entonces, incluido el del propio Inquisidor General Alonso Manrique y el del arzobispo de Toledo Alonso de Fonseca. En aquella conferencia, como es conocido, los representantes de la Universidad de Alcalá defendieron las ideas de Erasmo ${ }^{13}$. Sin embargo, el erasmismo ya estaba señalado como fuente potencial de herejías y durante la década de 1530 algunos de sus seguidores en Alcalá fueron sometidos a procesos inquisitoriales, unas veces acusados de alumbrados y otras de luteranos. La condición de cristiano nuevo fue entendida, cada vez más, como un indicio sólido de predisposición hacia la herejía.

En este ambiente, tan vivo y abierto como conflictivo, se formó Juan de Ávila, antes de lanzarse a ejercer su apostolado. Fuera de Alcalá, su primera misa como sacerdote la ofició en Almodóvar del Campo, donde muertos sus padres liquidó su rica herencia repartiéndola entre los pobres. Para celebrar la ocasión, nos dicen sus biógrafos, sentó a su mesa a doce pobres, renunciando a las costumbres habituales de festejar la ocasión con ricos y tumultuosos convites. Desde entonces viviría en la pobreza a imitación de los apóstoles, entregado a una intensa misión evangelizadora. Partió a Sevilla decidido a embarcarse hacia las Indias. La mayoría de sus biógra-

${ }^{12}$ Sobre la imposición de los estatutos de limpieza de sangre en la Universidad de Alcalá, véase Aguadé Nieto, «Juan de Ávila y el movimiento de Alcalá».

${ }^{13}$ Bataillon, Erasmo y España, 236-278. 
fos explican que el Inquisidor General Manrique, arzobispo de Sevilla, le obligó a quedarse en tierras de Andalucía y acometer aquí su propósito misionero. No hay que descartar que influyera en ello su condición conversa y la prohibición existente de viajar a Indias a los descendientes de judío ${ }^{14}$.

De esta manera comenzó la empresa del que fuera conocido después como el «Apóstol de Andalucía». Llevaba consigo buena parte de la experiencia adquirida en su etapa formativa en Alcalá. Aquí «leyó las obras de Erasmo y, aunque luego se aparte de él, lo seguirá citando a lo largo de otros escritos, como el Epistolario o el comentario que hace a la Carta a los Gálatas» ${ }^{15}$. El erasmismo que adoptó reforzaba su voluntad reformadora, la cual insistía en el mensaje evangélico que tan profundamente había estudiado en la Universidad de Alcalá, donde brillaba la cátedra de Sagradas Escrituras. Una forma de vivir la fe intimista y piadosa, muy presente en el ambiente de la ciudad del Henares, donde había grupos que practicaban el recogimiento y frecuentaban la comunión, la oración mental y la penitencia, no quedándose sólo en las formas externas y sensitivas del culto religioso colectivo.

Juan de Ávila además traía de Alcalá la determinación de vivir ejerciendo el apostolado, imitando a Cristo y a sus apóstoles, como tantos otros hombres que salieron de aquella ciudad con idéntica intención y que se repartieron por distintos lugares con un propósito semejante. Un apostolado que debía comunicarse al creyente por medio de una intensa predicación de sermones, siguiendo el consejo del apóstol Pablo, quien dijo que «la fe nos entra por el oído» (Rom 10:17) ${ }^{16}$. El apostolado también debía realizarse por medio de la comunicación oral y personal entre maestro y discípulos, buscando así formar nuevos apóstoles que dieran continuidad a la empresa emprendida; o en pláticas, conversando en pequeños círculos con devotos dispuestos a recibir el mensaje evangélico.

${ }^{14}$ Á. Huerga, O.P. «El Beato Ávila, imitador de San Pablo», Teología Espiritual IX (1965), 275; Juan de Ávila, Obras Completas, vol. I, 31-33.

${ }^{15}$ F. Martín HernándeZ, «Presentación» a Juan de Ávila, Audi, filia, ed. T. H. Martín y F. Martín Hernández (Madrid: BAC, 2010), XIX. Sobre el erasmismo en Juan de Ávila y sus raíces alcalaínas véase F. MARTín HernándEZ, ¿Fue erasmista san Juan de Ávila?, última lección en la Universidad Pontificia de Salamanca, 14 de mayo de 1998 (Salamanca, 1998).

${ }^{16}$ Juan de Ávila, Audi, filia, 99. 
Otras veces la comunicación con los discípulos era a través de la escritura, convertida en voz del maestro, que ofrece consejos y alumbra el camino a seguir en la renovación espiritual que les anuncia: ahí están los consejos por escrito a su joven discípula de la localidad de Écija, doña Sancha Carrillo, convertidos finalmente en su obra principal, Audi, filia, o los consejos que viajaron en forma de carta, recogidos después en su Epistolario espiritual.

\section{EXPERIENCIAS VIVIDAS Y REFLEJOS EN SU OBRA}

Tras su marcha de Alcalá de Henares cuando contaba alrededor de 26 años, Juan de Ávila llevaba también sobre sus espaldas la mácula de su «sangre cristiano nueva», y en buena medida su actividad y propuesta de reforma religiosa estuvo influida por esta cuestión, como hemos señalado ya, hipótesis que trataremos de explicar en las páginas que siguen. Se percibe en su vida y en su obra una singular respuesta a su experiencia personal como converso de judío, pero también como respuesta a la experiencia que compartió con muchos otros cristianos nuevos con quienes convivió estrechamente en un ambiente harto conflictivo a causa de este asunto. No sólo Alcalá de Henares, también Sevilla y las localidades andaluzas donde vivió y acometió su empresa tenían importantes contingentes de población cristiano nueva y, en consecuencia, la cuestión conversa era uno de los motivos de conflictividad social. No fue, sin duda, algo secundario o anecdótico del ambiente en el que vivió Juan de Ávila. Muy al contrario, considero que este fenómeno fue capital en su particular manera de abordar la realidad social y religiosa. Creo que leyendo su obra al calor de esta problemática pueden entenderse algunas de sus principales formulaciones, haciéndose además más comprensibles determinadas expresiones que reitera a lo largo de su obra. Entiendo, por otra parte, que este problema, tan presente en la época en la que vivió y tan cercano a sus propias experiencias vitales, determinaron algunos de sus escritos.

Veamos dos de los episodios más destacados de su biografía, como fueron su dura experiencia en la cárcel inquisitorial sevillana entre 1532 y 1533 o el frustrado encaje de la llamada «escuela avilista» con su querida Compañía de Jesús. Leamos al calor de estas difíciles experiencias algunas páginas de su obra en las que critica frontalmente la discriminación de los 
cristianos nuevos y la obsesión generalizada por la limpieza de sangre. Nos referiremos a varios capítulos de su Audi, filia y a un sermón suyo dedicado a la Natividad de la Virgen. En su Epistolario espiritual, por otra parte, podemos encontrar los consejos que da a quienes sufren acoso por su condición conversa. Y finalmente, podemos entender cuál fue la fórmula propuesta por Juan de Ávila para salvar aquel conflicto que corroía la sociedad y generaba tanto mal a los cristianos nuevos. La solución puede encontrarse leyendo con esta clave interpretativa que hemos propuesto algunos de sus tratados o sermones dedicados a los sacramentos, en los que recurre de forma reiterada a las cartas paulinas, dando un sentido singular a la metáfora del cuerpo místico de Cristo. Estos son los textos que hemos utilizado aquí para justificar nuestra interpretación, lo que no significa que pudieran espigarse algunos otros para completar o ampliar esta idea ${ }^{17}$.

Mal se conoce el proceso que la Inquisición de Sevilla llevó a cabo contra Juan de Ávila a causa de sus actividades misioneras en las localidades de Alcalá de Guadaira, Lebrija y, muy especialmente, en Écija. Para explicar los motivos de su procesamiento se han venido repitiendo las palabras del dominico fray Luís de Granada en la biografía que compuso de su querido y admirado maestro. En el capítulo que aquél dedica a las virtudes del santo destaca su paciencia ante las injurias recibidas, como las que le llevaron a la cárcel bajo la acusación de cerrar «la puerta de la salvación a los ricos y otras cosas de esta calidad» ${ }^{18}$. A mediados del siglo pasado Camilo Abad encontró en el Archivo Secreto Vaticano documentos inéditos relativos al proceso inquisitorial, perdido a día de hoy. Estos documentos nos dejan ver con más claridad cuáles eran las actividades cotidianas durante aquellos años de apostolado andaluz entre 1526 y 1532 y qué tipo de ideas defendía entonces en sus prédicas, pláticas y conversaciones íntimas ${ }^{19}$.

Además de negar la salvación a los ricos que desatendían la caridad con los pobres, Juan de Ávila fue acusado de «alumbrado». Algunos tes-

${ }^{17}$ J. I. Pulido, «Experiencia vital y elaboración de una fórmula conciliadora en la obra de Juan de Ávila», en Rincón (coord.), El Maestro Juan de Ávila. Aspectos del humanismo español del siglo XVI (en prensa).

${ }^{18}$ Fray Luís de Granada, Vida del Padre Maestro Juan de Ávila y las partes que ha de tener un predicador del Evangelio (Madrid: Edibesa, 2000), 117.

${ }^{19}$ C. M. ${ }^{\text {a }}$ AвAD, S.J., «Proceso inquisitorial contra el Beato Juan de Ávila. Estudio crítico a la luz de documentos desconocidos», Miscelánea Comillas 6 (1946), 95-167. 
tigos que asistieron a sus sermones o pláticas informales en Écija le acusaron ante los inquisidores de diversas proposiciones cercanas a esta doctrina herética, como era haber despreciado las oraciones vocales y cosas semejantes. El historiador dominico Álvaro Huerga, uno de los mejores conocedores de la historia de los alumbrados, explicó con detalle cómo las ideas de Juan de Ávila no sólo estaban muy lejos de los alumbrados, sino que además se mostró como uno de sus principales detractores ${ }^{20}$. Los inquisidores tampoco encontraron en sus ideas signos de herejía alumbrada. Pero ni la abismal distancia entre ricos y pobres, ni la floración de conventículos de «alumbrados» o «iluminados» eran las únicas causas de discordia social entonces. Había otros motivos de agitación social en los que Juan de Ávila expresó su opinión cuando vivió en Écija y en las localidades vecinas. Las conversiones al cristianismo de judíos desde finales del siglo XIV habían sembrado en las sociedades urbanas una profunda división social entre cristianos viejos y nuevos.

Por los documentos encontrados en el Vaticano sabemos que Juan de Ávila había preguntado a algunas mujeres que se confesaron con él en Écija si tenían odio a los confesos, es decir, a los cristianos nuevos. Así lo reconoció el propio Juan de Ávila ante los inquisidores cuando le interrogaron:

Respondió que muchas veces, confesando, ha hecho al penitente esta pregunta; como también, si tenía odio a los descendientes de los moros, por haber entendido que algunos no los tienen por prójimos; y así mismo, para reprenderles, a fin de que no llamen a los bautizados descendientes de infieles, perros moros o judíos (como demasiadas veces son llamados de sus amos con esos nombres), siguiéndose de este desprecio que algunos infieles no se cuidan de hacerse cristianos. Esta pregunta la hacía solamente a personas que creía tuvieran necesidad $^{21}$.

En otra ocasión, confesando a una vecina de nombre Leonor Gómez de Montesino, le preguntó si odiaba a los cristianos nuevos acusados ante la Inquisición, y tras contestar ésta de manera afirmativa, Juan de Ávila le

${ }^{20}$ Á. Huerga, O.P., «Conversos, alumbrados y tomismo en la escuela de Juan de Ávila»; IDEM, «Conversos y alumbrados en el huerto de Juan de Ávila», capítulo X de su Historia de los alumbrados, vol. V: Temas y personajes (1570-1630) (Madrid: Fundación Universitaria Española, 1994), 237-259.

${ }^{21} \mathrm{ABAD}$, «Proceso inquisitorial contra el Beato Juan de Ávila», 115-116. 
replicó que «muchos de los que eran quemados eran mártires». Ante los inquisidores explicó el sentido de estas palabras:

Respondió el siervo de Dios que, algunas veces, predicando y en pláticas particulares, había dicho que los que con paciencia sufrían la muerte que les daba la justicia, si morían con fe y en gracia, podía aquella pena serles como martirio.

Eran años de continuos autos de fe, en los que el mayor número de reos sentenciados en ellos eran cristianos nuevos acusados de «judaizar». Sin embargo, entre las víctimas no eran pocos los que morían como sinceros cristianos, llevados al cadalso bajo falsas acusaciones. Estos hombres y mujeres, explicaba abiertamente Juan de Ávila, junto a los que se arrepentían en el postrero lance, «del patíbulo volaban al cielo» ${ }^{22}$.

Por lo que conocemos del proceso inquisitorial contra Juan de Ávila se desprende una idea bastante clara de cuál fue su intervención en estos conflictos que envenenaban las sociedades urbanas de Andalucía. A través de sus sermones, pláticas, consejos y confesiones le vemos reprendiendo a los acusadores que, movidos por el odio y el orgullo linajudo, denunciaban a los cristianos nuevos o jaleaban sus penalidades. Le acusaron a la Inquisición por ello y tuvo que defenderse en este punto. Se estaba levantando una sociedad excluyente, donde la cultura y política blindaba un orden de privilegios para los cristianos viejos del que los conversos tenían que ser marginados ¿Dónde estaba el amor al prójimo que Cristo vino a predicar entre los hombres? ¿Qué clase de cristianismo era aquel al que le faltaba la compasión y la misericordia? El irenismo, la paz entre los cristianos, y la integración igualadora de todos los bautizados en una Iglesia renovada e inspirada en el mensaje paulino, chocaba de frente contra las aspiraciones de aquellos vecinos a los que predicaba y confesaba Juan de Ávila. Gentes concretas y vecinas que le delataron y acusaron ante el tribunal. Para ellos, muy al contrario, había una desigualdad o prelacía entre los cristianos, por la cual se distinguía a los cristianos viejos de los cristianos nuevos, calificados estos últimos de conversos o confesos, a los que odiaban y negaban su igualdad.

No sólo habló Juan de Ávila en Écija a quienes acosaban a los cristianos nuevos recriminándoles personalmente o en público su actitud. Tam-

\footnotetext{
${ }^{22} \mathrm{ABAD}$, «Proceso inquisitorial contra el Beato Juan de Ávila», 115.
} 
bién se dirigió a los que sufrían la persecución de sus vecinos por esta razón. De ello tenemos prueba escrita en su correspondencia. Leamos en su Epistolario espiritual su «Carta a unos devotos afligidos por una persecución que se había levantado». Está escrita desde la cárcel inquisitorial en la que Juan estuvo encerrado en Sevilla, prisión que le sirvió de experiencia personal para ahondar en el mensaje evangélico ${ }^{23}$. En cierta ocasión en la que unos discípulos le preguntaron cómo conocía tan profundamente las palabras de Pablo, les contestó que habían sido esos dos años de prisión entre 1532 y 1533 los que le habían llevado a reflexionar en profundidad sobre el mensaje evangélico, especialmente aquel que se expresaba en las cartas paulinas:

Y si vuestras mercedes estuvieran sentenciados a muerte con tres testigos contestes, como yo los tuve, ¿entendieran bien a san Pablo? ${ }^{24}$

Las tribulaciones que sufrían sus discípulos de Écija a los que dirigía la carta citada eran las mismas que le llevaron a él a la cárcel inquisitorial, y debían servirles como una oportunidad para experimentar y conocer mejor el mensaje de Cristo en la cruz. «Las persecuciones [...] que nos han venido [...] no han sido sino una prueba o examen de la lección que cinco o seis años ha que leemos» ${ }^{25}$. Juan de Ávila comienza su carta a sus sufridos discípulos de Écija citando las palabras que Pablo dedicó al Dios que «nos consuela en toda nuestra tribulación, para que nosotros podamos consolar a los que en toda angustia están» (2 Cor 1:11). Ellos, que habían sido perseguidos en Écija, y todos los que eran perseguidos por el odio de sus vecinos, debían consolar su pena volviendo la vista a Cristo en la Pasión. Debían tener

por dichoso de padecer algo por la honra de Aquel que sufrió tantas deshonras por sacarnos de la deshonra en que estábamos [...] ¡y cuán alta honra nos está aguardada por el abatimiento presente! [...] y cuán honrados somos en ser deshonrados por buscar la honra de $\operatorname{Dios}^{26}$.

${ }^{23}$ Juan de Ávila, Obras completas, vol. IV, 268-271: «Carta 58. A unos sus devotos, afligidos por una persecución que se había levantado (1532); animándolos mucho al amor de la cruz, a imitación de Cristo, de la cual imitación habla admirable y regaladamente».

${ }^{24}$ Huerga, «El Beato Ávila, imitador de San Pablo», 276.

${ }^{25}$ Juan de Ávila, Obras completas, vol. IV («Carta 58. A unos sus devotos»), 270.

${ }^{26}$ Juan de Ávila, Obras completas, vol. IV («Carta 58. A unos sus devotos»), 268. 
La premeditada reiteración que hace Juan de Ávila en este texto de las palabras honra/deshonra, así como la inversión del significado que de ellas hace, negando el que tenía en la época y negando también el sentido que se le da en la cultura dominante, no es casual, sino intencionado y, en nuestra opinión, quiere señalar la cuestión central del problema que está detrás del sufrimiento padecido por él y sus discípulos de Écija. La causa de aquel mal queda ocluida en el texto de su carta, pero conociendo el contexto social vivido en esa localidad durante aquellos años, creemos que se refiere a la división y enfrentamiento entre cristianos viejos y cristianos nuevos.

Así, la insistencia de Juan de Ávila en el vocablo e idea de la honra y de la deshonra es reflejo del lenguaje de la época en que vivió y se repite en otras partes de su obra. Era el lenguaje en el que la sociedad de esos años explicaba la diferencia que debía marcarse entre unos cristianos y otros: los puros, de ascendencia genética limpia y llamados por ende a gozar de la honra, y al margen, los impuros, de mácula en la sangre por su ascendencia judía, e incapacitados por ello al disfrute del reconocimiento público, viviendo como deshonrados. Aquel era el lenguaje de las delaciones y de la murmuración acusadora. El «bullicio del mundo», dirá Juan de Ávila en su Audi, filia. Los perseguidos por esta causa debían resignarse, decía Juan de Ávila a sus discípulos, y no levantar sus quejas en público. «Usad mucho el callar con la boca, hablando con los hombres» y abrir el corazón a la oración pensando en los sufrimientos de Cristo, que con su padecer les dejó limpios, y ahora les sigue limpiando con lengua de malos, como estropajos, la que tienen aquellos que les acusan ${ }^{27}$. Nos os quejéis, no protestéis, continúa diciéndoles, tomemos estos sufrimientos del presente como una feliz ocasión para dar un pequeño sorbo de lo que vivió Cristo en la cruz y sigamos lo que nos enseñó en su pasión, sin quejas ni protestas. Y, por último, no olvidéis perdonar a vuestros enemigos, les dice Juan de Ávila. Esa era la fórmula evangélica que Juan de Ávila les proponía a sus discípulos cristianos nuevos para sobrellevar la persecución.

Explica fray Luís de Granada en su biografía de Juan de Ávila que estando éste en la cárcel un amigo suyo, miembro de la Inquisición, le aconsejó que tachara a sus acusadores como enemigos. Era una manera de abreviar el proceso y de asegurar su exculpación. No aceptó el consejo.

${ }^{27}$ Juan de Ávila, Obras completas, vol. IV («Carta 58. A unos sus devotos»), 271. 
En su carta a sus discípulos les dice que padezcan con gozos y amen a sus enemigos, aquellos que les persiguen. Cristo en la cruz perdonó a quienes le daban aquel sufrimiento. Del mismo modo, Juan de Ávila perdonaba a sus enemigos de Écija sin recusarles, a quienes

yo en ese pueblo he predicado [...] como san Pablo [...], [y por quienes] tengo gran compasión de su ceguedad [...], por la deshonra que me dan, o por mejor decir, dar quieren [...]. [Y continúa diciendo a sus discípulos], yo no pienso que otra honra hay en este mundo sino ser deshonrado por Cristo. [...] Acordaos cuántas veces habéis oído de mi boca que hemos de amar a nuestros enemigos ${ }^{28}$.

Honra, Deshonra y Limpieza en el Audi, FILIA de JuAn de Ávila

Que aquellas discordias a causa de la división social entre cristianos viejos y nuevos eran un motivo principal en las meditaciones de Juan de Ávila lo demuestra que lo abordase como una cuestión fundamental en su obra más importante, el Audi, filia. A este tema dedica los primeros capítulos de su libro, el segundo, el tercero y el cuarto, y vuelve sobre este asunto al final del libro, en el capítulo 99. En estos textos Juan de Ávila aconseja al lector que huya de las honras del mundo y no sufra por la deshonra recibida de sus semejantes. Es una de las críticas más directas y contundentes contra la cultura que entroniza el linaje de la sangre que podemos encontrar en la literatura del siglo XVI español.

Juan de Ávila quizás escribiera ya en la cárcel las primeras páginas de su Audi, filia y no cabe duda que estaba influenciado por sus vivencias de esos primeros años de apostolado andaluz. Como se sabe el libro nace como respuesta al ruego de una muchacha joven a la que visitaba, doña Sancha Carrillo, hermana de un discípulo suyo de Écija, Pedro Fernández de Córdoba, clérigo e hijo de los señores de Guadálcazar. La joven doncella le pidió consejo espiritual y él le fue dando aquellos pliegos escritos que tanto gustaron a sus seguidores. En ellos quedó resumido lo que en-

\footnotetext{
${ }^{28}$ Juan de Ávila, Obras completas, vol. IV («Carta 58. A unos sus devotos»), 270271.
} 
tendía por cristianismo ${ }^{29}$. En 1556, un impresor de Alcalá de Henares lo publicó sin su permiso, y tres años después la Inquisición lo incluía en el Índice de libros prohibidos (1559) por sus ideas de regusto erasmista y por cierta aproximación en algunos puntos a las propuestas de Lutero ${ }^{30}$. Todo aquello lo pulió Juan de Ávila en la reescritura que hizo de su texto, en la que ajustó sus ideas a los acuerdos doctrinales que se estaban terminando de perfilar en el Concilio de Trento. El texto definitivo fue impreso cinco años después de su muerte, en $1574^{31}$.

Oye, hija, y ve, e inclina tu oreja, y olvida tu pueblo, y la casa de tu padre. Y cobdiciará el rey tu hermosura.

Con el Salmo 44 comienza Juan sus consejos a sus discípulos para que sigan la correcta vida cristiana, dirigiendo su voz primero a su discípula de Écija. Los primeros cinco capítulos los dedica a explicar que para escuchar la voz de Dios es necesario, antes que nada, no oír «el lenguaje del mundo $[. .$.$] porque es todo mentiras». Este es el lenguaje que impone al$ individuo el valor de las honras y de las deshonras mundanales. «La tiranía de la honra mundana $»^{32}$, titula Juan de Ávila el capítulo $2^{\circ}$, o de forma más extensa: «Que no debemos oír el lenguaje del mundo y honra vana; y cuán grande señorío tiene sobre los corazones que la siguen, y lo [que] será el castigo de los tales» ${ }^{33}$. Comienza su capítulo negando el sentido y el significado que los hombres del siglo XVI dan a la honra:

El lenguaje del mundo no le hemos de oír, porque es todo mentiras, y muy perjudiciales para quien las creyere, haciéndole que no siga la verdad que es, sino la mentira que tiene apariencia y se usa. Y con esto, engañado el hombre, echa tras sus espaldas a Dios y a

${ }^{29}$ «El Audi, fili fue la obra de juventud de san Juan de Ávila, henchida del fervor religioso un tanto erasmista de Alcalá, con ansias de reforma y de purificación de la Iglesia. Iba entonces a la búsqueda de un cristianismo sincero e íntimo dentro del más puro Evangelio, sin trabas ni adherencias posteriores», MARTín HeRnándeZ, «Presentación» a Audi, filia, XIX.

${ }^{30}$ Martín HernándeZ, «Presentación» a Audi, filia, XVI-XVII.

${ }^{31}$ Juan de Ávila, Obras completas, vol. I, 169-192.

${ }^{32}$ Así aparece titulado este capítulo $2^{\circ}$ en la edición de Martín y MARTín HernándeZ, Audi, filia, 9.

${ }^{33}$ Juan de Ávila, Obras completas, vol. I, 540. 
su santo agradamiento, y ordena su vida por el ciego norte del aplacimiento del mundo, y engéndrasele un corazón deseoso de honra y de ser estimado de hombres; semejable al de los antiguos soberbios romanos, de los cuales dice san Agustín que por amor de la honra mundana deseaban vivir, y por ella no temieron morir ${ }^{34}$.

La alusión que hace Juan de Ávila a las circunstancias de su tiempo nos resulta evidente. El hombre de 1530 había dado la espalda a Dios para buscar el reconocimiento público, la estima y reputación social, la honra, por la cual vivía y moría, e incluso hacía guerra a sus vecinos. « Oh honra vana, condenada por Cristo en la cruz a costa de sus grandes deshonras! $\gg^{35}$. Las semejanzas con el texto de su carta dirigida a sus discípulos que hemos leído más arriba son llamativas. Aquel era el primer y gran mal de la época, y nadie lo sabía mejor que aquellos que habían sido perseguidos por los amadores de la honra vana, idólatras que habían hecho ídolo de la honra y movido a guerra contra sus víctimas a causa de ella $^{36}$. Detrás de aquellas palabras puede verse el ambiente de las ciudades andaluzas, los enfrentamientos habidos en Écija, entre los hombres y mujeres a los que Juan de Ávila predicaba y confesaba.

El capítulo $3^{\circ}$ lleva el siguiente título en la edición de 1574: «De qué remedios nos habemos de aprovechar para despreciar la honra vana del mundo, y de la grande fuerza que Cristo da para la poder vencer» ${ }^{37}$. «Escucha, hija», dice Juan de Ávila al hombre de su tiempo, para vencer la vana honra hay que mirar a Cristo en la cruz y verle «tan lleno de deshonras» ${ }^{38}$. Él eligió voluntariamente esa muerte con la que quiso enseñar cuán vano era el esfuerzo de muchos que guardaban en su corazón un gran amor a las honras del mundo. Así, nos dice Juan de Ávila, Cristo advirtió y criticó con su pasión aquel orden de cosas que regía la vida de los hombres del siglo XVI:

Y no sin causa eligió el Señor muerte en extrema deshonra, sino porque conoció cuán poderoso tirano es el amor de la honra en el

\footnotetext{
${ }^{34}$ Juan de Ávila, Obras completas, vol. I, 540-541.

${ }^{35}$ Juan de Ávila, Obras completas, vol. I, 541.

${ }^{36}$ Juan de Ávila, Obras completas, vol. I, 541-542.

${ }^{37}$ Juan de Ávila, Obras completas, vol. I, 542.

${ }^{38}$ Juan de Ávila, Obras completas, vol. I, p. 543.
} 
corazón de muchos; que no dubdan de ponerse a la muerte, y huyen del género de la muerte, si es con deshonra. Y para darnos a entender que no nos ha de espantar lo uno ni lo otro, eligió muerte de cruz, en la cual se juntan graves dolores con excesiva deshonra ${ }^{39}$.

El corazón grande, dice, debe despreciar el ser preciado o despreciado por los demás, y la verdadera virtud es la de quien hace buenas obras sin buscar el reconocimiento ajeno. Despliega aquí Juan una teología de la abnegación. Citando a Pablo en su carta a los Hebreos escribe: «Salgamos a Cristo fuera de los reales, imitándole en su deshonra» (Heb 13:13). Tal y como enseñó Cristo en la cruz, les dice Juan a sus discípulos, muchos de ellos cristianos nuevos como él, deben mostrar un sincero «desprecio de la honra vana del mundo», ya que de tal manera nada podrán hacer contra ellos sus enemigos.

El capítulo $4^{\circ}$ de la edición de 1574 del Audi, filia lleva el siguiente título: En qué grado, y por qué fin, es lícito desear la humana honra; y del grandísimo peligro que hay en los oficios honrosos y de mando. La respuesta viene de nuevo de la mano de san Pablo, para quien la muerte de Cristo nos da la respuesta: «cuya cruz él tenía por honra suprema» (Gal 6,14). Hay que mirar la honra con desapego de corazón, no desearla ni buscarla, mucho menos con dineros, y si ya se tiene, no gloriarse de ella, porque «la experiencia nos ha mostrado que las dignidades y lugares de honra muy pocas veces han hecho de malos buenos, y muy muchas de los buenos malos» ${ }^{40}$. La experiencia vivida por la sociedad de aquel tiempo enseñaba multitud de ejemplos en este sentido: gentes acaudaladas, que después de amasar dineros, conseguían comprar al rey honras en forma de títulos de caballería, de hidalguía u otra clase de nobleza, honras en forma de cargos públicos en el gobierno municipal, títulos de regidor, jurado o de algún otro oficio. Eran muchos los «atrevidos en meterse en señoríos, y mandos y honras» ${ }^{41}$. Esta fue una dinámica social característica del siglo XVI, que fue causa de enconados conflictos entre personas, familias y grupos, los cuales competían por alcanzar la honra, un bien limitado en el mercado de lo venal. Pero si aquella conquista del reconocimiento

\footnotetext{
${ }^{39}$ Juan de Ávila, Obras completas, vol. I, p. 543.

${ }^{40}$ Juan de Ávila, Obras completas, vol. I, p. 545.

${ }^{41}$ Juan de Ávila, Obras completas, vol. I, p. 546.
} 
público hacía al hombre ser bien visto por sus vecinos, no necesariamente le hacía bueno. Muchos, al contrario, batallando para conseguir aquellos honores terminaban cayendo en el mal y apartándose de Dios. Por tal motivo, Juan de Ávila aconseja huir de ellos.

En el capítulo 99, titulado De la vanidad de la nobleza del linaje, y que no se deben gloriar de él los que quieren ser del linaje de Cristo, Juan de Ávila da una explicación firme y clara de sus ideas acerca de la virtud, de la honra y de la limpieza o impureza de sangre de los distintos linajes de aquella sociedad ${ }^{42}$. En páginas inmediatamente anteriores a este capítulo Juan de Ávila había acudido a las palabras de san Agustín y a la metáfora de las dos ciudades: en primer lugar está la ciudad de los hombres que se aman a sí mismo hasta despreciar a Dios, esa es ciudad terrenal; y en segundo lugar está la ciudad de los hombres que aman a Dios amando a sus prójimos: ellos son los que habitan en la ciudad celestial. Así, Juan de Ávila les repite a sus discípulos: «Olvidad vuestro pueblo», ciudad terrenal habitada por los hombres ciegos de vanidad: «No querría que os cegase a vos la vanidad que a muchos ciega, presumiendo de su linaje carnal» ${ }^{43}$. Juan de Ávila propone a quienes le escuchan y leen abandonar los usos sociales de aquel tiempo y despreciar los linajes genéticos que dan continuidad biológica a ascendientes y descendientes. Les aconseja que no hagan como quienes «gloríanse en el cuerpo y en el origen de su linaje» ${ }^{44}$. Con ello se muestra contrario a la tendencia general de su tiempo, tan adornada de blasones, escudos heráldicos y árboles genealógicos de gente reputada que rezumaba orgullo por la nobleza de la sangre. Aquellos eran linajes carnales, «linajes vanos», dice Juan de Ávila, que fundamentan la nobleza del hombre en el cuerpo y en la carne.

La nobleza y honra transmitida de cuerpo a cuerpo, de generación a generación, dentro un mismo linaje son despreciadas por Juan de Ávila, y así aconseja que hagan sus seguidores. ¿Cómo presumir socialmente del cuerpo cuando éste fue «tan vergonzosamente engendrado, que es asco pensallo y vergüenza decillo». El cuerpo, «vil muladar», está «lleno de

\footnotetext{
${ }^{42}$ Juan de Ávila, Obras completas, vol. I, 752-754.

${ }^{43}$ Juan de Ávila, Obras completas, vol. I, 752.

${ }^{44}$ Juan de Ávila, Obras completas, vol. I, 752.
} 
mil necesidades», además de ser «perezoso»y «malicioso», el «mayor enemigo que tenemos», el «mayor traidor que nunca se vio». La carne, que se hereda de los padres, «es cosa para haber vergüenza y temor» ${ }^{45}$. Cosa de burla son, exclama Juan de Ávila voceando al mundo con vehemencia, los vanidosos que presumen del origen y del linaje de su carne, del cuerpo heredado de sus mayores. No se nos puede escapar lo que hay detrás de sus palabras, ni podemos dejar de ver en su risa dolida la ironía al comprobar cómo en su sociedad, la del siglo XVI, los linajudos hacían gala de su superioridad social, moral y religiosa sobre el resto. Lo hacían, recordemos, argumentando la limpieza y pureza de su sangre, cuando en realidad, a los ojos de Dios, lo que hacían era glorificar la suciedad de su carne.

Las palabras de Juan de Ávila son un grito de aliento a los que sufrían por su condición conversa en una sociedad que se esforzaba por excluirlos de los distintos estados de la honra: del estado eclesiástico, del estado noble, del servicio al rey en su administración.

La estima en que Dios os tiene [les dice a todos, aunque escribía a doña Sancha Carrillo, la doncella de Écija], no es por vuestro linaje, mas por ser cristiana; no por nacer en la sala entoldada, mas por tornar a nacer en el santo bautismo. El primer nacimiento es de deshonra; el segundo es de honra. El primero, de vileza; el segundo, de nobleza ${ }^{46}$.

Olvidad vuestro pueblo, repite una y otra vez Juan de Ávila a sus seguidores, aquel pueblo en el que vivís infamados, y entrad en la ciudad celestial para consolaros en el mensaje evangélico. Según este mensaje, entre los bautizados no puede haber diferencia alguna ya que el bautismo elimina toda diferencia. Dios crió las ánimas de todos los hombres, y éstas no se heredan como ocurre con la carne del cuerpo; Cristo igualó a todos los bautizados con los beneficios de su muerte. Por lo tanto, y éste es el mensaje fundamental de Juan de Ávila a sus seguidores, afligidos en la discriminación: «los que eran antes desiguales por honras del mundo, son igualmente vestidos con nobleza de honra celestial y divina». Es un grito de aliento y ánimo, con el que les quiere empujar para que continúen

\footnotetext{
${ }^{45}$ Juan de Ávila, Obras completas, vol. I, 752-753.

${ }^{46}$ Juan de Ávila, Obras completas, vol. I, 753.
} 
en su camino, sin detenerse por el abatimiento que les pueda provocar el lenguaje que escuchan en el mundo en el que viven, en sus respectivas ciudades andaluzas. Ellos, deshonrados en el mundo por su linaje de carne maculado con la «sangre judía» de sus ancestros y por sus orígenes biológicos impuros, habían recibido con el bautismo la honra verdadera, la cual reciben por voluntad de Dios y por los méritos de Cristo en la cruz. No hay razón para el desaliento, les dice a los perseguidos por su condición conversa; no hay motivo para perseguirlos ni discriminarlos, les dice al resto. La idea del doble nacimiento que Juan de Ávila explica en este capítulo 99 del Audi, filia, el nacimiento carnal, que da linajes biológicos, y el nacimiento espiritual, que hace cristianos igualados a través del bautismo, es su argumento evangélico con el que ataca radicalmente la cultura de la limpieza de sangre.

\section{UN SERMÓN CONTRA EL LINAJE CARNAL: «ESTO ES HONRA: SER DEL LINAJE ESPIRITUAL DE JESUCRISTO»}

Juan de Ávila volvió sobre este punto en un sermón predicado para conmemorar la Natividad de la Virgen, el cual posteriormente apareció publicado en la edición realizada en Madrid en 1596 por su discípulo y pariente P. Juan Díaz ${ }^{47}$. Tras citar las palabras del evangelista Mateo en las que éste se refiere a la genealogía de Jesús, Juan de Ávila comienza su sermón preguntándose en voz alta: «¿para qué mandáis, Señor, contar vuestro linaje?» ${ }^{48}$ «¿Qué ha Dios con linaje?», insiste más adelante en lo que será el tema central de su prédica: «¿para qué mandáis escrebir aqueso, pues por otra parte nos mandáis que despreciemos la carne, linaje y toda honra?». Tras repasar el árbol genealógico de Cristo, Juan de Ávila nos dice «que hubo en él tantos malos, que antes hay en él deshonra que honra» ${ }^{49}$. Así, pues, nada bueno garantiza el linaje de Jesucristo si lo miramos según la carne. Entre sus ascendientes biológicos hubo idólatras

\footnotetext{
${ }^{47}$ Juan de Ávila, Obras completas, vol. III, 822-842: «Esto es honra: ser del linaje espiritual de Jesucristo» (Sermón a la Natividad de la Virgen, 8 de septiembre). Sobre las primeras ediciones de los sermones, ibíd., XXIII-XXI.

${ }^{48}$ Juan de Ávila, Obras completas, vol. III, 823.

49 Juan de Ávila, Obras completas, vol. III, 823.
} 
como Ajaz y crueles asesinos como Manasés, y sin embargo a Jesús nada se le pegó de las maldades de sus antepasados.

Por el contrario, dice Juan de Ávila, es el linaje espiritual el que importa, como proclamó Pablo: «Convirtamos el linaje de la carne al linaje del espíritu, la generación a la generación del espíritu, y veremos qué es lo que movió al evangelista de contarnos el linaje de Jesucristo, qué es el linaje espiritual de Jesucristo». ${ }^{50}$ De nuevo, Juan de Ávila acude a la idea del doble nacimiento, el carnal o biológico por un lado, y el espiritual por otro, aunque en este sermón el segundo nacimiento no ocurra por medio del bautismo sino a través de la fe, de creer lo que Dios nos dice.

Nos interesa la definición que Juan de Ávila hace en su sermón de lo que entiende por hidalguía y honra. De nuevo, subido en el púlpito, se lanza contra la cultura mayoritaria defensora de la limpieza de sangre. Ser hidalgo, honrado y limpio se alcanza entrando a formar parte del linaje espiritual de Jesucristo por medio de la fe: «Esto es lo que Dios alaba y tiene en algo [...] Esto es ser hidalgo, el que es del linaje espiritual de Jesucristo, ése es el hidalgo honrado $»^{51}$. La crítica a las ideas dominantes de su tiempo no puede ser más radical: la sangre y la carne no trasmiten la honra de unos individuos a otros a través del linaje. Que aquello lo dijera en sus sermones delante de sus oyentes, desde el púlpito, de manera tan directa y contundente, nos advierte de sus ideas críticas y de su actitud beligerante frente a un problema medular en la época. Por otro lado, el hecho de que este sermón fuera recogido a finales del siglo XVI para darlo a la imprenta en una primera edición, la de 1596, y en otras posteriores, hizo posible que sus ideas quedaran fijadas sobre el papel, asegurando así su permanencia en el tiempo.

Sólo unos pocos sermones de los muchos que predicó Juan de Ávila han conseguido llegar hasta nosotros. Muchos otros, hoy desaparecidos, circularon en su época en copias manuscritas. Recordemos que Juan de Ávila fue, sobre todo, un predicador e hizo del sermón su principal instrumento de apostolado y una de sus más importantes fórmulas de comunicación. ¿Cuántas otras ideas y palabras, perdidas para siempre, no dedicó a esta cuestión?

\footnotetext{
${ }^{50}$ Juan de Ávila, Obras completas, vol. III, 825-826.

${ }^{51}$ Juan de Ávila, Obras completas, vol. III, 826.
} 
«LOS HUMORES DE LA TIERRA»: LOS ESCRÚPULOS FRENTE A LOS CONVERSOS EN LA Compañía de Jesús

El abatimiento, el amargo silencio impuesto sobre uno mismo, la actitud huidiza ante la realidad adversa, éstas son algunas de las características con las que se ha descrito la actitud de muchos conversos del siglo XVI ante al hostigamiento que sufrieron. Fue una actitud de defensa frente a un ambiente cada vez más generalizado de rechazo a los hombres de ascendencia judía, los llamados cristianos nuevos. «El dolor de Ávila ante estas discriminaciones raciales [...] fue inmenso», escribe Huerga ${ }^{52}$. Como se ha dicho ya, Juan de Ávila descendía de judíos por línea paterna, circunstancia conocida en su tiempo y que le fue tenida en cuenta. El suyo no es un caso aislado en aquel siglo sino que, incluso, «entre sus discípulos abundan los de análoga condición» ${ }^{53}$. Ciertamente, el apostolado de Juan de Ávila en Andalucía atrajo a muchas gentes de condición conversa, unos como discípulos, otros como meros devotos o simpatizantes suyos. Éste fue uno de los rasgos que caracterizó su escuela, y si tenemos en cuenta lo dicho hasta aquí, esta peculiaridad de los «avilistas» debió ser una consecuencia lógica de su ferviente y pública defensa de las gentes de esta condición.

Esta circunstancia cobró un especial relieve en los contactos entre la «escuela avilista» y la recién fundada Compañía de Jesús. Como es sabido, las relaciones entre Juan de Ávila e Ignacio de Loyola fueron cercanas, por respeto mutuo y simpatía, por afinidad personal y por compartir ambos un proyecto semejante de renovación religiosa a través del apostolado. Es sabido que hubo intentos de integrar a Juan de Ávila en la Compañía de Jesús y, también, de fusionar a los «avilistas» con los jesuitas. Para acometer esta tarea Ignacio de Loyola encomendó desde Roma los contactos iniciales al primer jesuita de Alcalá de Henares, Francisco de Villanueva ${ }^{54}$. En 1552 éste escribía a Ignacio sobre el asunto: «Yo

${ }^{52}$ Huerga, «El Beato Ávila, imitador de San Pablo», 273.

${ }^{53}$ Huerga, «El Beato Ávila, imitador de San Pablo», 273.

${ }^{54}$ Sobre Francisco de Villanueva y los primeros años de presencia jesuítica en Alcalá, véanse C. LóPEz PEGO, «Domicilios, recursos materiales y bienhechores de los jesuitas de Alcalá entre 1543 y 1633», Anales Complutenses 21 (2009), 205-236; y A. VERDOY, «El jesuita padre Francisco de Villanueva (1509-1557), prototipo de un nuevo apóstol en la 
pensé ir este verano a ver al Maestro Ávila [...]; después [...] me encogí, porque Ávila también tiene su raza $»^{55}$. Villanueva, fundador en Alcalá de Henares del colegio más importante que la Compañía tuvo en España en aquel tiempo, sentía simpatía por los cristianos nuevos: «yo querría tener fuerzas para me hacer procurador de ellos, máxime vemos el día de hoy en ellos más virtuosos que en los viejos ni hidalgos» ${ }^{56}$. Los cristianos nuevos, reconocía, tenían más virtud y más afición por el mensaje evangélico que predicaban quienes apostaban por la reforma espiritual que muchos de los linajudos, embebidos en las vanidades del mundo y apegados a las formas más externas y superficiales de la vida religiosa.

Sin embargo, y pese a su declarada simpatía por los conversos, Francisco Villanueva se encogió y decidió no visitar a Juan de Ávila aquel verano de 1552 por su «mácula judía». Su actitud, prudente o timorata, respondía a la grave situación que estaba tomando el asunto de la «limpieza de sangre» en España en esos años, y al temor de que aquel ambiente hostil pudiera afectar negativamente a los intereses concretos de los jesuitas. Seguimos en estas líneas el revelador trabajo de Bataillon sobre los primeros años de la Compañía en España ${ }^{57}$. El propio Francisco de Villanueva había estado en Toledo, negociando personalmente con el arzobispo Juan Martínez Silíceo, autoridad eclesiástica bajo la cual estaba sujeto el colegio jesuita de Alcalá de Henares así como los otros centros que se estaban fundando en la misma diócesis. El arzobispo Silíceo no había disimulado entonces su profunda aversión hacia los cristianos nuevos. Pelearía con arrojo en el cabildo de la catedral de Toledo para implantar los estatutos de limpieza de sangre por los cuales se excluiría a los cristianos nuevos de cualquier cargo o beneficio eclesiástico en su diócesis. El ejemplo de Toledo, sede primada, marcaba un nuevo tiempo en este asunto para el conjunto de la iglesia hispana ${ }^{58}$.

Castilla de la Reforma católica», Espacio, Tiempo, Forma. Serie IV. Historia Moderna 9 (1996), 87-115 (reimpr. Manresa 68 [1996], 405-428).

${ }_{55}^{5}$ Monumenta Historica Societatis Ihesu [= MHSI], Ep. Mixtae, II, 786, cit. HuErGA, «El Beato Ávila, imitador de San Pablo», 273.

${ }^{56}$ El documento autógrafo de Villanueva a Ignacio de Loyola está fechado a 15 de noviembre de 1551. MHSI, Ep. Mixtae, II, 625-626, cit. Batalllon, Los jesuitas en la España del siglo XVI, 212.

${ }^{57}$ Bataillon, Los jesuitas en la España del siglo XVI, 193-236.

${ }^{58}$ Sobre el problema de la limpieza de sangre y el protagonismo que adquirió el 
Aquello fue, en gran medida, una apuesta personal de Silíceo. Villanueva pudo comprobar en persona la determinación del arzobispo en este punto y entendió de sus labios que su oposición a que los jesuitas se asentaran en su territorio diocesano era por la buena disposición que tenían a aceptar a los cristianos nuevos entre sus filas. Efectivamente, la Compañía, al igual que había empezado a hacer Juan de Ávila años antes, reclutó a sus primeras hornadas de discípulos entre la burguesía mercantil de las ciudades y entre los grupos acomodados de las pequeñas localidades, entre quienes abundaban los cristianos nuevos.

Villanueva se lo explicaba con detalle a Ignacio de Loyola: «El arzobispo ha hablado claro en esta segunda vez que fuimos yo y el doctor Torres a le hablar. Por ventura pensó que yo tenía raza de confeso, que así los llama él [...] comenzó a decir que nos quemaría a todos [...] y que él pretendía que no hubiese cura ni beneficiado que fuese de esta casta, ni pudiese confesar ni predicar» ${ }^{59}$. El jesuita Araoz, sobrino de Ignacio de Loyola, también había recibido el mismo mensaje de Silíceo cuando le visitó: «El arzobispo de Toledo ha hecho grande instancia para que, a lo menos en las casas y colegios de su diócesis, no recibamos cristianos nuevos, y que si alguno hay, lo pasemos a otra parte y dicen que, haciendo esto, hará grandes cosas por la Compañía» ${ }^{60}$. La negativa de Villanueva a seguir las palabras del arzobispo de Toledo les valió a los jesuitas la prohibición de predicar y confesar en Alcalá, además de otros impedimentos para progresar en su deseado arraigamiento local.

«Los humores de acá», escribía el jesuita Araoz sobre la aversión generalizada a los conversos. Aquellos humores podían ser un problema grave que echara por tierra la deseada implantación de los jesuitas en España. Esta fue una de las razones fundamentales, a decir por Bataillon, que hizo fracasar el intento de fusión entre la «escuela avilista» y la Compañía de Jesús, proyecto que se abordó entre unos y otros en los años de

arzobispo Martínez Silíceo en los debates y legislación sobre esta cuestión remito a HeRnÁNDEZ Franco, Sangre limpia, sangre española, 97-123.

${ }^{59}$ Bataillon, Los jesuitas en la España del siglo XVI, 212.

${ }^{60}$ MHSI, Ep. Mixtae, III, 656, cit. BATAILlon, Los jesuitas en la España del siglo XVI, 214. 
1549 a $1555^{61}$. Juan de Ávila deseaba dejar su obra como herencia a la Compañía: numerosos colegios, alrededor de quince, fundados por él en distintas ciudades andaluzas y una legión de discípulos que desde ellos desempeñaban su misión de apostolado.

La condición de converso de Juan de Ávila y la de muchos de sus seguidores eran un escollo que dificultaba este propósito de fusión. El jesuita Nadal, por cuyas manos pasó también este negocio, destacaba esta circunstancia en su correspondencia con Ignacio de Loyola:

El Maestro Ávila es persona de mucha habilidad natural, y de buenas letras y buen espíritu, de mucho fructo que el Señor le ha dado en esta Andalucía, y de gran autoridad y crédito, no sólo en la Andalucía, más en el resto de España: es de cristianos nuevos y ha sido tomado por la Inquisición, mas liberado sin nota alguna [...] Síguenle muchos cristianos nuevos, no sólo los que siguen su consejo, de diversos estados, mas también de los que le siguen modo semejante al nuestro ${ }^{62}$.

Éstas eran las características que Nadal, tras su encuentro personal en Córdoba, resaltaba de Juan de Ávila y de sus seguidores. Tales aspectos debían ser tenidos muy en cuenta, advertía, a la hora de sopesar los beneficios y los perjuicios que traería la fusión. El exceso de libertad en la organización, rasgo singular de la «escuela avilista», las libertades de palabra que sus miembros se tomaban en sus prédicas y apostolado, los problemas que algunos de ellos tuvieron con la Inquisición y, especialmente, la abundancia de confesos entre sus filas eran los principales obstáculos que aparecían en el camino. Finalmente se frustró el deseo de Juan de Ávila de, en palabras del jesuita Francisco de Borja, «dejar por heredera a la Compañía de sus discípulos en los colegios» ${ }^{63}$.

Juan de Ávila se sintió profundamente decepcionado por este fracaso. En diversas ocasiones expresó su malestar por los escrúpulos que mostraban los jesuitas. Se lo hizo saber a Ignacio de Loyola por carta y a todos los jesuitas

${ }^{61}$ Bataillon, Los jesuitas en la España del siglo XVI, 223-230.

${ }^{62}$ MHSI, Ep. Nadal, I, 226-227, cit. Bataillon, Los jesuitas en la España del siglo XVI, 222-223.

${ }^{63}$ MHSI, Ep. Borgiae, III, 128, cit. Batalllon, Los jesuitas en la España del siglo XVI, 229. 
que le visitaron. Forzó en alguna ocasión a que se aceptara el ingreso en la Compañía de algún discípulo suyo, como fue el caso de Luís de Santander, cristiano nuevo originario de Écija. Otras veces se resignó a sacrificar a sus discípulos cristianos nuevos para que la Compañía se hiciera cargo de algún colegio por él fundado, como fue el caso del colegio de Granada. El escaso resultado de aquellos esfuerzos, de las negociaciones mantenidas para alcanzar una solución, debieron generar en Juan de Ávila una profunda frustración.

Pero si poco había conseguido en la defensa de sus discípulos cristianos nuevos en este proyecto concreto, a través de sus escritos elaboraría y difundiría una solución doctrinal válida para todos ellos: una solución que ofrecía razones teológicas suficientes para superar aquel problema social y religioso de manera categórica y universal. Para ello volvía al Nuevo Testamento, concretamente a las cartas paulinas, y desde ellas al significado de la muerte de Cristo en la cruz.

\section{El CUERPO Místico DE CRISTO}

En los sermones que Juan de Ávila dedicó al santísimo sacramento, recogidos y editados por Juan Díaz en 1596, podemos encontrar la respuesta que propuso para superar el problema converso que enfrentaba a unos con otros en la sociedad del siglo XVI. Nos interesan aquí especialmente dos de estos sermones, los que llevan los núms. 52 y 53 en la edición de Sala Balust y Martín Hernández ${ }^{64}$. En ellos Juan de Ávila desarrolla con todo detalle la metáfora evangélica del cuerpo místico de Cristo y le da un sentido singular, para convertirla en solución teológica al problema que estamos explicando ${ }^{65}$. Como hizo en el transcurso de su vida y obra, Juan de Ávila sigue el mensaje de Pablo en sus epístolas, en las cuales el apóstol expone en repetidas ocasiones la dicha metáfora, cuyo significado es, sobre todo, la unión armoniosa, pacífica e igualitaria de todos los cristianos a pesar de las diferencias de cada uno ${ }^{66}$.

${ }^{64}$ Juan de Ávila, Obras completas, vol. III.

${ }^{65}$ C. Stuczynski, «Pro-converso apologetics and Biblical Exegesis», en J. Decter y A. Prats (ed), The Hebrew Bible in Fifteenth Century Spain: Exegesis, Literature, Philosophy and the Arts (Leiden: Brill, 2012), 151-176.

${ }^{66}$ F. CArrillo Rubio, «El cuerpo místico en la doctrina del Apóstol de Andalucía», Manresa XVII (1945), 202-235. 
El sermón núm. 52 lo dedica a explicar la unión entre Cristo y todos los cristianos que le reciben a través de los sacramentos, en este caso, el de la eucaristía. Misterio sacramental, nos dice Juan de Ávila, que se desvela recurriendo a las epístolas paulinas, al que declara seguir en este sermón: «La metáfora que en este presente sermón nos ha de dar lumbre para el conocimiento de este sagrado misterio, nos la dio Dios por boca del apóstol San Pablo» ${ }^{67}$. Cristo es la cabeza del cuerpo único que forman todos los cristianos, sin diferencia alguna entre ellos. Los méritos alcanzados por Cristo en la cruz son comunicados a todo el cuerpo, cuyos miembros se benefician de la gracia todos por igual, sin distinción posible. Como en los capítulos del Audi, filia que hemos citado anteriormente, aparece otra vez con llamativa insistencia un lenguaje propio del siglo XVI, un «lenguaje del mundo», que en boca de Juan de Ávila es transformado en lenguaje divino, al invertir el significado de las palabras. Este es el método que sigue Juan de Ávila en su obra: transmutar el significado de las palabras utilizadas por el hombre en el siglo, criticando y negando el sentido que éste les da, para acto seguido elevarlas a una dimensión divina en las que cambia su valor, devolviéndoselas así al hombre, por medio de su voz en el púlpito o de la letra en sus escritos. Estas palabras que se repiten hasta convertirse en conceptos principales de su pensamiento son honra, deshonra y limpieza, vocablos que en el siglo XVI tenían un sentido muy preciso que a nadie se le escapaba y que hacían referencia a la distinción y prelacía entre los cristianos de acuerdo a su origen genealógico: cristianos viejos por un lado, honrados y limpios; y cristianos nuevos, maculados, no limpios y deshonrados.

Sin embargo, escribe Juan de Ávila, en el cuerpo místico de la Iglesia, del cual Cristo es la cabeza, no hay distinción alguna entre quienes se incorporan a él por medio de la eucaristía. Cristo es la fuente de toda limpieza, y al incorporarse el cristiano en él a través del bautismo y, después, de la comunión, queda limpio de toda suciedad.

A los deshonrados en Adán nos es dado Cristo como cabeza ${ }^{68}$ : $¡$ Oh, alabado seas, mi Dios y Señor, para siempre, fuente de toda limpieza, del cual y por el cual son limpios todos los que lo son! $!^{69}$.

${ }^{67}$ Juan de Ávila, Obras completas, vol. III, 673-685 (Sermón 52: «En Cristo levantamos la cabeza», 673).

${ }^{68}$ Juan de Ávila, Obras completas, vol. III, 673.

${ }^{69}$ Juan de Ávila, Obras completas, vol. III, 680. 
Cristo es fuente de limpieza, de la verdadera honra, la honra divina y no la mundana, la cual es comunicada a todos los cristianos, quienes forman un único cuerpo con él:

Yo soy mi deshonra, porque te ofendí; y soy tu deshonora, porque fui causa que te deshonrasen por mí: y tú, Señor, con tu deshonra me honraste; y a boca llena te alabo y confieso por honra mía ${ }^{70}$.

En este sermón Juan de Ávila repite también imágenes que nos hablan de enemigos que acusan y que difaman a otros con imputaciones referidas a la falta de limpieza y de honra. «Muchos son los que me acusan», nos dice, pero no hay peligro en el refugio seguro del cuerpo místico:

Veis aquí claro lo que estaba oscuro; Dios humanado es cabeza, y los suyos son su cuerpo; y cabeza y cuerpo son una misma cosa. Ser la Cabeza perdonada, librada del infierno, heredada del Cielo, es ser todo esto los que son su cuerpo ${ }^{71}$.

Semejantes ideas y este mismo lenguaje se repite como tema central en su sermón núm. 53 dedicado también al santísimo sacramento, que lleva por título «El hombre y Cristo, una misma persona, un Cristo» ${ }^{72}$. De nuevo, Juan de Ávila recurre a Pablo para aclarar el sentido de la metáfora del cuerpo místico. La Iglesia, dice, está compuesta por diversidad de hombres, algunos incluso con una autoridad que no tiene el resto, pero la gracia de Cristo es para todos igual sin exclusión alguna. Ni el más bajo de los linajes, explica Juan de Ávila, queda al margen de la gracia divina, que se renueva en el hombre por medio de la comunión:

mas si un hombre pobre, de vil linaje, esclavo, y si otra cosa más baja se puede pensar, recibiere en buen estado aquel sacratísimo cuerpo de nuestro Señor Jesucristo, es levantado de su bajeza, y a trueco del nombre que antes tenía es hermoseado y honrado con nombre de Jesucristo ${ }^{73}$.

Por Cristo y en Cristo, incorporándose en su cuerpo místico, todo hombre, independientemente de su linaje, alcanza la honra. Éste fue su mensa-

\footnotetext{
${ }^{70}$ Juan de Ávila, Obras completas, vol. III, 677-678.

${ }^{71}$ Juan de Ávila, Obras completas, vol. III, 682-683.

72 Juan de Ávila, Obras completas, vol. III, 686-699.

${ }^{73}$ Juan de Ávila, Obras completas, vol. III, 692.
} 
je. Leamos ahora al apóstol Pablo en su epístola primera a los Corintios, tan citada por Juan de Ávila, poniendo nuestra mente en esas localidades andaluzas donde Juan de Ávila le imitaba, Écija por caso:

Del mismo modo que el cuerpo es uno y tiene muchos miembros, y todos los miembros del cuerpo, por muchos que sean, no forman más que un cuerpo, así también Cristo. Porque todos nosotros, judíos o no judíos, esclavos o libres, hemos recibido un mismo Espíritu en el bautismo, a fin de formar un solo cuerpo [...] los miembros del cuerpo que consideramos más débiles son los más necesarios, y a los que consideramos menos nobles, los rodeamos de especial cuidado. Asimismo, tratamos con mayor decoro a los que consideramos más indecorosos, mientras que los que son presentables no lo necesitan. Dios mismo distribuyó el cuerpo dando mayor honor a lo que era menos noble para que no haya divisiones en el cuerpo, sino que todos los miembros se preocupen los unos de los otros [1 Cor 12,12-25].

La ciudad de Corintio, donde Pablo lanzó su mensaje, no era ni Sevilla ni ninguna de las ciudades andaluzas donde predicaba Juan de Ávila, imitador consciente y voluntario del apóstol. Pero había algunas similitudes entre sus respectivas sociedades. En la ciudad abierta y cosmopolita de Corintio, centro portuario y comercial asomado al Mediterráneo, Pablo fundó la primera comunidad cristiana, atravesada entonces por fuertes tensiones y divisiones. Sus cartas proponen fórmulas para mantener la paz y la unidad interna, expresadas en la metáfora del cuerpo místico de Cristo. Juan de Ávila, apóstol de Andalucía, insistió en esta imagen unitaria y llevó el mensaje paulino a unas sociedades urbanas, la de Sevilla y las de ciudades vecinas, fuertemente divididas por los enfrentamientos entre linajes de cristianos viejos y de cristianos nuevos de judío. No escribió textos como el de su compañero y amigo, el fraile dominico Domingo de Valtanás, quien entró a lidiar en el debate de los estatutos de limpieza de sangre con un breve y conocido tratado. Sin embargo hay un lenguaje, unas figuras y un fondo común en ambos religiosos y en sus respectivas propuestas ${ }^{74}$.

Pero los textos de Juan de Ávila vuelan más alto y transcienden el problema concreto para elevarse por encima de él. No dejó por ello de referirse

${ }^{74}$ Domingo de Valtanás, Apología sobre ciertas materias morales en que hay opinión y apología de la comunión frecuente, eds. Á. HuERGa y P. SAInz Rodríguez (Barcelona: Juan Flors, 1963). Sobre las relaciones entre Ávila y Valtanás he tratado en PuLIDo, «Experiencia vital y elaboración de una fórmula conciliadora» (en prensa). 
a esta cuestión en distintos momentos de su vida y en diversas partes de su obra. Criticó con argumentos evangélicos el concepto mundano de la limpieza de sangre, aquel que se fue imponiendo en la sociedad durante el siglo XVI, en la cultura mayoritaria y en el ordenamiento jurídico. Envió, al mismo tiempo, un mensaje de paciente y cristiana resignación a quienes como él sufrían dolor y hostigamiento por esta causa. Y finalmente, recogiendo el mensaje paulino, de quien se declara fiel seguidor, elabora a partir de la metáfora del cuerpo místico una solución teológica con la que superar aquel problema social. Siguiendo los pasos de su vida y la lectura de sus textos podemos ver cómo Juan de Ávila definió una forma de cristiandad inclusiva, unitaria y en paz, de apasionado mensaje evangélico, que bebe en las epístolas paulinas y alza su mirada a Cristo en la cruz, cabeza de un solo cuerpo, integrado por todos los bautizados, independientemente de sus diferentes orígenes y linajes.

Esa fue la propuesta de Juan de Ávila a una división social que existía entre los cristianos de su tiempo y que era causa de un sinfín de males. Como converso había vivido aquella dolorosa experiencia en sus propias carnes; y como hombre consciente y comprometido con su tiempo conocía bien el problema y se enfrentó a él, con su obra y con sus escritos. Con este recorrido por las páginas de algunos de sus textos principales hemos querido destacar un aspecto poco conocido por quienes han trabajado sobre este religioso; hasta la fecha, tampoco se ha acudido a él cuando se ha abordado el estudio del problema de la limpieza de sangre o del fenómeno converso. En nuestra opinión, este aspecto debe incorporarse en su lugar correspondiente para entender mejor una y otra $\operatorname{cosa}^{75}$.

Recibido: $16 / 03 / 2012$

Aceptado: 15/11/2013

${ }^{75}$ Stefania Pastore, una de las últimas historiadoras que se ha ocupado de las relaciones entre la espiritualidad española del siglo XVI y el problema converso, en su reciente libro dedicado a este tema, minucioso y brillante, no contempla el aspecto que nosotros proponemos aquí cuando aborda la figura y obra de Juan de Ávila, S. PASTORE, Una herejía española. Conversos, alumbrados e inquisición (1449-1559) (Madrid: Marcial Pons, 2010), 334-340. 